Check for updates

Cite this: Nanoscale Adv., 2019, 1, 3443

\title{
Novel nitrogen doped carbon dots enhancing the anticorrosive performance of waterborne epoxy coatings $\dagger$
}

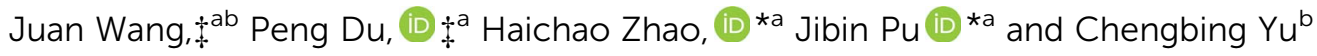

There are lots of research studies reporting the excellent performances of waterborne epoxy resin coatings to reduce environmental VOC levels. However, it has also been manifested that waterborne epoxy resin coatings do not have high corrosion resistance because of being hydrophilic. Herein, we utilized a kind of $\mathrm{N}$ doped carbon dot $(\mathrm{N}-\mathrm{CD}$ ) which has high ethanol solubility and low cytotoxicity to enhance the corrosion resistance of waterborne epoxy resin coatings as a nanofiller. The $\mathrm{N}$-CDs were obtained through a solvothermal method by using 4-aminosalicylic acid (ASA) as a precursor. The diameter and height of N-CDs confirmed by scanning probe microscopy and transmission electron microscopy are 3$5 \mathrm{~nm}$. Corrosion resistance performance of the coatings without and with $\mathrm{N}$-CDs is investigated by electrochemical impedance spectroscopy by immersing them in $3.5 \mathrm{wt} \% \mathrm{NaCl}$ (aq) for 70 days. The results indicate that the composite coatings with 0.5 wt $\% \mathrm{~N}-\mathrm{CDs}$ show superior anticorrosive performance due to bond interactions between $\mathrm{N}-\mathrm{CDs}$ and polymer chains, the defect repairing effect of $\mathrm{N}-\mathrm{CDs}$ and the formation of compact $\mathrm{Fe}_{2} \mathrm{O}_{3}$ and $\mathrm{Fe}_{3} \mathrm{O}_{4}$ passivation layers.
\end{abstract}

Received 12th March 2019

Accepted 8th July 2019

DOI: 10.1039/c9na00155g

rsc.li/nanoscale-advances droplets in a continuous phase of water, has many advantages over solvent-borne epoxy coatings. ${ }^{12,13}$ First, it exhibits strong adaptability and high adhesion to many metal substrates; second, it meets the demands of environmental protection due to the low content of organic solvents or volatile organic compounds. Last but not least, it ensures high crosslinking density. ${ }^{\mathbf{1 4 - 1 6}}$ So it is safe enough during storage or transportation which greatly improves its use. However, it should be noted that an epoxy coating only acts as a barrier in metal protection. It is key to prepare a composite coating with a barrier effect and other functions such as self-healing and corrosion inhibition.

Recently, carbon dots (CDs), a kind of carbon-based fluorescent (FL) nanomaterial with low cytotoxicity, significant water solubility and superior corrosion inhibition properties, have attracted ever-increasing attention. ${ }^{17,18}$ Song et al. demonstrated a facile synthesis of $\mathrm{N}$-doped carbon dots (N-CDs) for cell imaging and $\mathrm{Fe}^{3+}$ detection. ${ }^{19}$ Zhao's group reported water soluble carbon dots as an effective corrosion inhibitor for carbon steel. ${ }^{\mathbf{2 0}}$ Besides, Zhu et al. applied carbon dots as nanofillers to endow healing properties in bulk polymers and described their anticorrosion properties. ${ }^{21}$ Now, the inhibiting effect of CDs is worthy of paying attention to in the field of metal protection. First, many hydrophilic functional groups such as carboxyl groups on the surface of CDs make them significantly soluble in water. ${ }^{22}$ Therefore, they have good compatibility in waterborne epoxy coatings which can effectively fill the defects caused by the process of solvent evaporation. ${ }^{23}$ Second, CDs with amino groups as a type of adsorbent film corrosion inhibitor can be adsorbed by the surface charge of the metal
${ }^{a}$ Key Laboratory of Marine Materials and Related Technologies, Zhejiang Key Laboratory of Marine Materials and Protective Technologies, Ningbo Institute of Materials Technology and Engineering, Chinese Academy of Sciences, Ningbo 315201, China.E-mail: zhaohaichao@nimte.ac.cn; pujibin@nimte.ac.cn

${ }^{b}$ School of Materials Science and Engineering, Shanghai University, Shanghai 200444, China

$\dagger$ Electronic supplementary information (ESI) available: See DOI: 10.1039/c9na00155g

\$ These authors contributed equally to this work. 
and form a monomolecular film throughout the anode and cathode regions. ${ }^{20}$ Thence, they prevent the corresponding electrochemical reaction and protect the metal surface from severe corrosion. Furthermore, the $\mathrm{C}=\mathrm{O}-\mathrm{NH}$ covalent bond formed between CDs and polymer chains, the hydrogen bond formed between functional groups and the van der Waals forces of $\mathrm{CDs}^{21}$ enhance the flexibility and self-healing ability of the resin structure.

Herein, a simple, versatile, and cost-effective methodology is reported for initiating interfacial bonding in bulk polymers: the introduction of carbon dots (CDs) into a polymer matrix forming a composite coating. To explore prospective applications, we further evaluated the morphology, chemical structure and crystal configuration of the N-CDs. The anti-corrosion performance is studied by electrochemical impedance spectroscopy (EIS) in $3.5 \mathrm{wt} \% \mathrm{NaCl}$ aqueous solution. Besides, the corrosion products are investigated by scanning electron microscopy (SEM) and energy dispersive spectroscopy (EDS) to reflect the anti-corrosion mechanism. These results prove that $\mathrm{N}-\mathrm{CD}$ nanocomposite coatings have a significant corrosion protective performance on carbon steel.

\section{Experimental section}

\subsection{Materials}

4-Aminosalicylic acid (ASA) and ethanol were purchased from Aladdin Industrial Corporation. Epoxy resin (E-51) and waterborne curing agents were provided by Sichuan Honglizhan Chemical Co., Ltd. Deionized (DI) water was used during the whole experiment. Q235 carbon steel $(10 \mathrm{~mm} \times 10 \mathrm{~mm} \times 10$ $\mathrm{mm}$ ) was used as the corrosion testing substrate. Before testing, carbon steel was polished with 500 and 1500 SiC sand papers to gain smooth surfaces, then washed with ethanol and DI water via ultrasonic vibration several times, and finally dried in a vacuum environment.

\subsection{Synthesis of N-CDs}

$\mathrm{N}$-CDs were obtained using a similar method reported by Song et al. ${ }^{19}$ ASA (0.6 g) was first dissolved in $60 \mathrm{~mL}$ of ethanol with stirring, and then moved into polytetrafluoroethylene autoclaves and kept at $200{ }^{\circ} \mathrm{C}$ for $18 \mathrm{~h}$ in an oven. Then dark brown solutions were obtained after cooling down to room temperature. In order to remove nonreactive molecules, dialysis bags (molecular weight cut-off $\sim 3.0 \mathrm{kDa}$ ) were used to purify the prepared solution for one day. DI water should be changed every $3 \mathrm{~h}$, and finally N-CDs were obtained as a black solid after rotary evaporation and drying under vacuum and have better solubility in ethanol.

\subsection{Preparation of N-CDs-EP composite coatings}

A certain amount of N-CD powder was completely dissolved in $10 \mathrm{~mL}$ of ethanol with ultrasonication, and then a precalculated amount of the waterborne curing agent was added to the above solution and carefully mechanically stirred for $30 \mathrm{~min}$. After removing ethanol by rotary evaporation, a stoichiometric amount of E51 epoxy (the mass ratio between E51 epoxy and waterborne curing agents was at $2: 3$, Table S1†) was added to the polymer matrix. After removing trapped air bubbles through degassing in a vacuum oven, the mixture was mechanically stirred vigorously with a high speed blender for 5 min. Finally, the mixture was coated on the Q235 steel surface with a wire bar coater and cured at room temperature $\left(25^{\circ} \mathrm{C}\right)$ for $48 \mathrm{~h}$ to obtain N-CDs-EP composite coatings with a thickness of $50 \mu \mathrm{m}$. Besides, pure EP coatings were prepared for comparison by the same procedure without N-CD nanoparticles as mentioned above. These samples were named pure EP, $0.5 \% \mathrm{~N}$ CDs-EP, $1.0 \% \mathrm{~N}-\mathrm{CDS}-\mathrm{EP}$ and $2.0 \% \mathrm{~N}-\mathrm{CDs}-\mathrm{EP}$ according to the content of N-CDs.

\subsection{Characterization}

The microstructure and morphology of N-CDs were characterized by transmission electron microscopy (TEM, FEI Tecnai F20) and scanning probe microscopy (SPM, Vecco Dimension 3100). Fourier transform infrared spectrometry (FTIR, THERMO Nicolet 6700), X-ray diffraction (XRD, BRUKER D8 ADVANCE), UV-vis absorption spectroscopy (Perkin-Elmer Lambda 950), Raman spectroscopy (Renishaw inVia Reflex) and X-ray photoelectron spectroscopy (XPS, Axis Ultra DLD) were used to confirm the chemical composition and structure of N-CDs. The coating matrix was investigated by scanning electron microscopy (SEM, Hitachi S4800) and differential scanning calorimetry (DSC, DSC 214). Electrochemical impedance spectroscopy (EIS) was performed on a $\mathrm{CHI660 \textrm {E }}$ electrochemical station in $3.5 \mathrm{wt} \% \mathrm{NaCl}$ solution using a three-electrode system, where, the test samples were used as the working electrode, a Pt plate was used as the counter electrode and the saturated calomel electrode (SCE) was used as the reference electrode, respectively. The corrosion potential ( $\left.E_{\text {corr }}\right)$ of the Q235 steel specimens was obtained from the open circuit potential in the balance state of the system. The EIS plots were plotted in the frequency range of $10^{5}$ to $0.01 \mathrm{~Hz}$ and the sinusoidal voltage signal amplitude was $20 \mathrm{mV}$. The final corrosion parameters from the EIS data were fitted with ZsimpWin software. The surface morphology and chemical composition of the substrates after 70 days of immersion in $3.5 \mathrm{wt} \% \mathrm{NaCl}$ solution were obtained with scanning electron microscopy (SEM, FEI Quanta FEG 250), energy dispersive spectroscopy (EDS) and Xray diffraction (XRD).

\section{Results and discussion}

\subsection{Materials properties}

3.1.1 Synthesis of N-CDs. The preparation of N-CDs can be completed by heating ASA in ethanol at $200^{\circ} \mathrm{C}$ for $18 \mathrm{~h}$ and then using a tubular dialysis membrane for purification as shown in Fig. $1{ }^{19}$ We demonstrated that the resulting N-CDs could be homogeneously dispersed in ethanol, producing a dark brown solution as shown in Fig. S1. $\uparrow$ The N-CDs showed significant dispersibility through this solvothermal preparation.

3.1.2 Micro morphology of N-CDs. In general, as known to us, transmission electron microscopy (TEM) and scanning probe microscopy (SPM) were used to confirm the morphology 


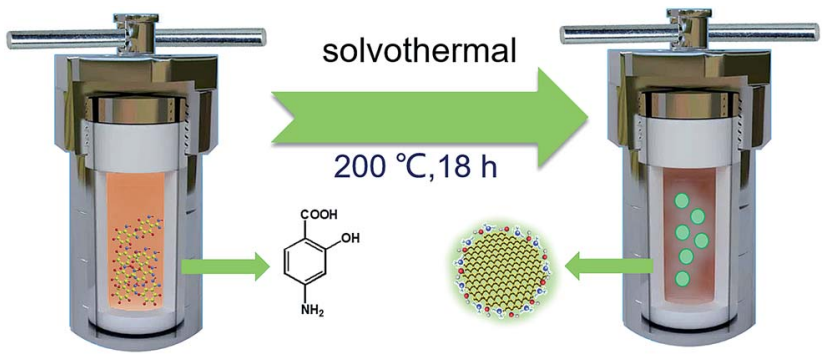

Fig. 1 Schematic illustration of the preparation of N-CD nanomaterials.

and height of the prepared $\mathrm{N}-\mathrm{CDs},{ }^{24}$ respectively. In order to prove repeatability and uniform topography, each measurement was done three times.

As shown in Fig. 2a, N-CDs have an average diameter of about $3 \mathrm{~nm}$ with a uniform spherical structure. In addition, the high-resolution TEM image of N-CDs provides the highly crystalline structure with well-resolved lattice fringes with a (100) interplanar lattice spacing of $0.21 \mathrm{~nm}$, corresponding to the (001) plane of graphite in N-CDs. ${ }^{18}$ SPM can measure the height of N-CDs, as revealed in Fig. 2b, and the height of N-CDs is approximately $3-5 \mathrm{~nm}$ which is similar to the results in Fig. $2 \mathrm{a}$.

3.1.3 Characterization of materials. The FTIR spectrum was used to characterize ASA and N-CDs (Fig. 3a). ASA exhibits stretching vibrations of $\mathrm{O}-\mathrm{H}$ in the range of $3495 \mathrm{~cm}^{-1}$ and stretching vibrations of $\mathrm{N}-\mathrm{H}$ in amino groups at $3387 \mathrm{~cm}^{-1}$. The strong and broad absorption bands at $2534-3008 \mathrm{~cm}^{-1}$ and $1616 \mathrm{~cm}^{-1}$ are assigned to $\mathrm{C}-\mathrm{H} \mathrm{C}=\mathrm{O}$, and $\mathrm{N}-\mathrm{H}$ stretching vibrations, respectively. The peaks centered at $1448 \mathrm{~cm}^{-1}$ and $1293 \mathrm{~cm}^{-1}$ are attributed to the $\mathrm{C}-\mathrm{N}$ and $\mathrm{C}-\mathrm{O}$ bonds. The peak at $818 \mathrm{~cm}^{-1}$ is assigned to the bending vibration of the $\mathrm{C}-\mathrm{H}$ bond belonging to the benzene ring. ${ }^{19}$ As expected, N-CDs have the same functional group as ASA and therefore show unreacted $\mathrm{O}-\mathrm{H}$ and $\mathrm{N}-\mathrm{H}$ groups at around $3380 \mathrm{~cm}^{-1}$ and $\mathrm{C}-\mathrm{O}$ stretching and $\mathrm{C}-\mathrm{H}$ bonds of the benzene ring at $1239 \mathrm{~cm}^{-1}$ and $838 \mathrm{~cm}^{-1}$, respectively. However, we also found that the

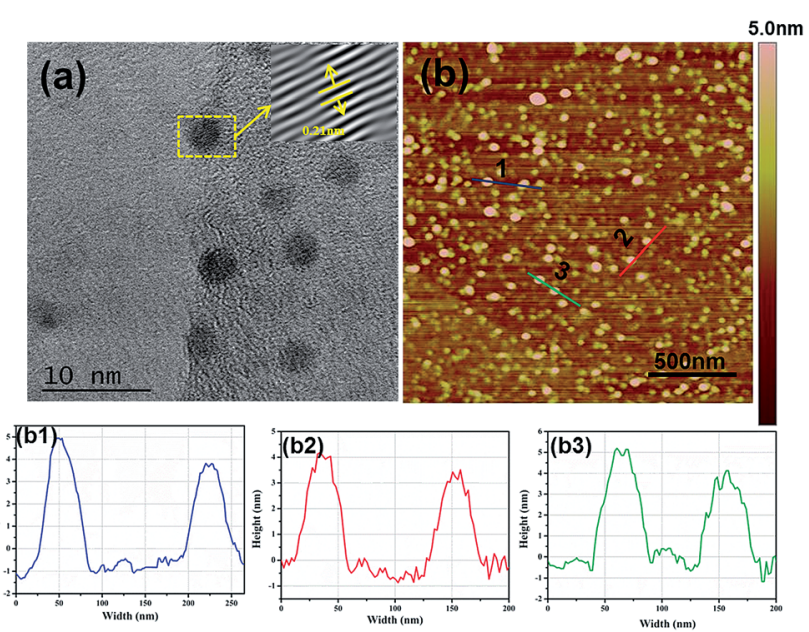

Fig. 2 (a) TEM and (b) SPM images and topography of N-CDs.
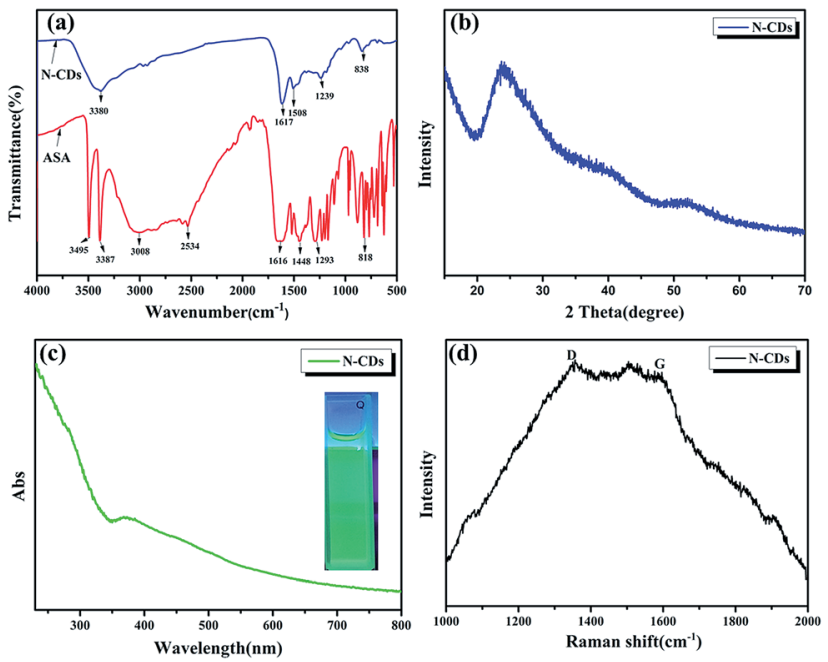

Fig. 3 (a) Fourier transform infrared (FTIR) spectra, (b) XRD pattern of $\mathrm{N}-\mathrm{CDs}$, (c) UV-vis absorption spectra of N-CDs and (d) Raman spectrum.

peak at $1617 \mathrm{~cm}^{-1}$ corresponds to $\mathrm{NH}_{2}$ deformation vibrations and that at $1508 \mathrm{~cm}^{-1}$ denotes $\mathrm{C}=\mathrm{C}$ vibrations which are the unique functional groups of N-CDs due to the carbonization reaction. ${ }^{25}$ The N-CDs were characterized via wide-angle X-ray scattering analysis, as shown in Fig. 3b. A broad peak centered at $2 \theta=24^{\circ}$ in the XRD spectra indicated that they had an amorphous carbon structure due to the introduction of nitrogen and oxygen. The interlayer spacing of N-CDs was $0.370 \mathrm{~nm}$, broader than that of graphite $(0.34 \mathrm{~nm}){ }^{26}$ This is consistent with the results of TEM. UV-vis spectroscopy was applied to detect the optical properties of the N-CDs. As shown in Fig. 3c, the UV-vis absorption spectra of the sample shows an absorbance at $280 \mathrm{~nm}$ and $370 \mathrm{~nm}$ due to the $\pi \rightarrow \pi^{*}$ and $\mathrm{n}$ $\rightarrow \pi^{*}$ transitions of certain sub-fluorophores included in the CDs (e.g. $-\mathrm{NH}_{2}$ and $\mathrm{C}-\mathrm{N}=\mathrm{C}$ ), respectively. ${ }^{27,28}$ In addition, the $\mathrm{N}-\mathrm{CDs}$ emit green light under $365 \mathrm{~nm}$ UV excitation which has strong fluorescence as shown in the inset in Fig. 3c. The high fluorescence may also disturb Raman characterization. The Raman spectra of N-CDs showed a G band at $1590 \mathrm{~cm}^{-1}$ and a $\mathrm{D}$ band at $1350 \mathrm{~cm}^{-1} \cdot{ }^{29} \mathrm{In}$ general, the $\mathrm{D}$ band represents the low-carbon lattice structure (defect degree) of the carbon materials, and the $\mathrm{G}$ band is the light level band of $\mathrm{sp}^{2}$ hybridized carbon atoms, which was not obvious in Fig. 3d. This phenomenon (more pronounced D-band) may be due to the strong photoluminescence interference under the visible near-infrared wavelength excitation.

$\mathrm{X}$-ray photoelectron spectroscopy (XPS) is used to analyze the chemical composition and structure of N-CDs. The full XPS spectra of N-CDs shown in Fig. 4a demonstrate that N-CDs are certainly composed of carbon, nitrogen and oxygen. The fine structure spectrum of C 1s (Fig. 4b) exhibits three chemically shifted peak components at $284.5,285.6$ and $288.2 \mathrm{eV}$ attributed to $\mathrm{C}-\mathrm{C}, \mathrm{C}-\mathrm{O} / \mathrm{C}-\mathrm{N}$ and $\mathrm{C}=\mathrm{N} / \mathrm{C}=\mathrm{O}$, respectively. Similarly, the two peaks in the fine structure spectrum of $\mathrm{N}$ 1s (Fig. 4c) are assigned to $\mathrm{C}-\mathrm{N}-\mathrm{C}(399.2 \mathrm{eV})$ and $(\mathrm{C})_{3}-\mathrm{N}(400.2 \mathrm{eV})$, and the two 

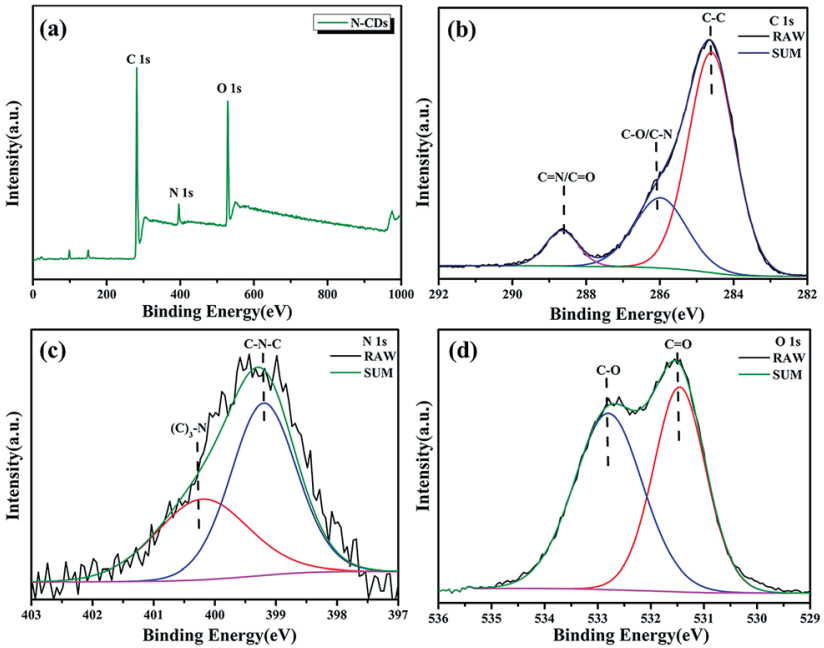

Fig. 4 XPS wide spectra of (a)N-CDs, (b) C 1s, (c) N 1s, and (d) O 1s

peaks for $\mathrm{O} 1 \mathrm{~s}$ are ascribed to two kinds of $\mathrm{O}$ atoms $(\mathrm{C}=\mathrm{O}(531.5$ $\mathrm{eV}$ ) and $\mathrm{C}-\mathrm{O}(532.8 \mathrm{eV})$ ) (Fig. $4 \mathrm{~d}){ }^{30}$

\subsection{Characterization of N-CDs-EP composite coatings}

3.2.1 Morphology of N-CDs-EP composite coatings. The prepared composite coatings applied to the electrode were dried and pre-immersed in liquid nitrogen for few seconds, and then broken to observe the cross-sectional morphologies by SEM, as shown in Fig. 5. From the SEM image (Fig. 5a), the surface of the pure waterborne epoxy resin coating is porous and unevenly fractured which was due to water evaporation when the coating was dried. ${ }^{31}$ The surface of the N-CDs-EP composite coating (Fig. $5 \mathrm{~b}$ and c) became smooth because the suitable N-CDs as a nano-filler have filled the pores and defects. The dispersion of $\mathrm{N}$-CDs in the EP matrix was also studied by TEM (Fig. S2 $\uparrow$ ), and the results confirmed that the compatibility between N-CDs and the epoxy matrix was perfect (after adding to $0.5 \%$ and $1.0 \% \mathrm{~N}$ CDs). However, excess N-CDs interact with the molecules (Fig. S3 $\dagger$ ) and increase the flaws (Fig. 5d).
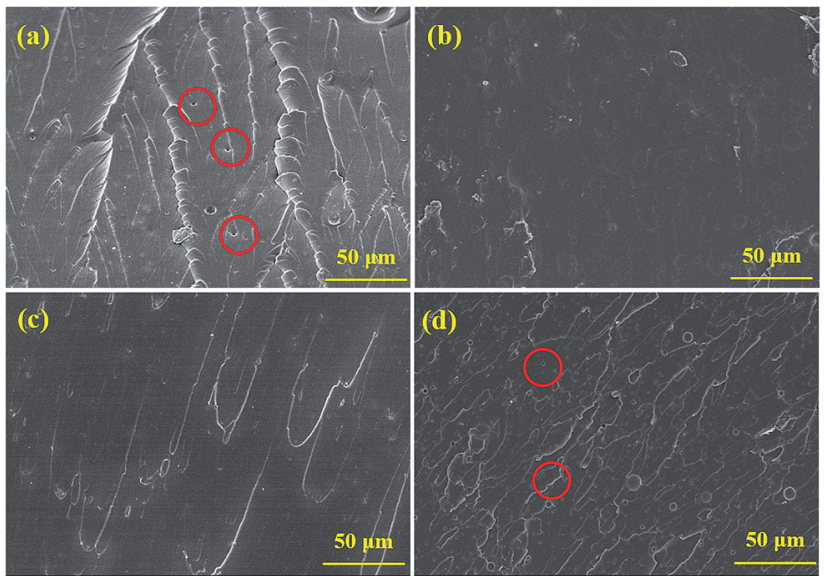

Fig. 5 Cross-sectional morphology of coatings: (a) pure EP; (b) $0.5 \%$ $\mathrm{N}-\mathrm{CDs}-\mathrm{EP}$; (c) $1.0 \% \mathrm{~N}-\mathrm{CDs}-\mathrm{EP}$; (d) $2.0 \% \mathrm{~N}$-CDs-EP.
3.2.2 Thermodynamic properties. A DSC- $T_{\mathrm{g}}$ test was performed on the N-CDs-EP coating and EP coating. The effect of the addition of $\mathrm{N}$-CDs on the glass transition temperature of the two-component epoxy resin coatings was investigated. ${ }^{32}$ The results are shown in Fig. 6. The glass transition temperatures $\left(T_{\mathrm{g}}\right)$ of the $0.5 \% \mathrm{~N}-\mathrm{CDs}-\mathrm{EP}, 1.0 \% \mathrm{~N}-\mathrm{CDs}-\mathrm{EP}$ and $2.0 \% \mathrm{~N}-\mathrm{CDs}-\mathrm{EP}$ coatings were $68.1{ }^{\circ} \mathrm{C}, 70.0{ }^{\circ} \mathrm{C}$ and $63.2{ }^{\circ} \mathrm{C}$, respectively. They were significantly higher than the glass transition temperature of the pure waterborne epoxy coating (pure EP) $\left(58.2^{\circ} \mathrm{C}\right)$. The incorporation of $\mathrm{N}-\mathrm{CDs}$ increases the reactivity of the resin, increases the crosslink density of the system, and fills in the defects formed by the aqueous epoxy resin during the curing process, thus leading to an increase in the $T_{\mathrm{g}}$ of the aqueous epoxy resin coating. ${ }^{33}$ The value of the glass transition temperature $\left(T_{\mathrm{g}}\right)$ of $2.0 \% \mathrm{~N}-\mathrm{CDs}-\mathrm{EP}$ decreased compared to $1.0 \% \mathrm{~N}$ CDs-EP because excessive N-CDs will increase the defects of the waterborne epoxy coating.

\subsection{Anticorrosion properties of N-CDs-EP composite coatings}

3.3.1 Electrochemical impedance spectroscopy analysis of N-CDs-EP composite coatings. EIS measurements were used to observe the corrosion behaviors of N-CDs-EP systems at different immersion times. ${ }^{34}$ The as-tested Nyquist and Bode impedance plots of different coating systems after 70 days of immersion in $3.5 \mathrm{wt} \% \mathrm{NaCl}$ solution are shown in Fig. 7. The Nyquist plots of four coating systems showed a shrinking capacitive loop with prolonged immersion time, suggesting the decline of corrosion-protection performance for steel (Fig. 7a1d1). ${ }^{35}$ However, the incorporation of the filler increased the capacitor arc radius. The greater capacitive loop of $0.5 \% \mathrm{~N}-\mathrm{CD}-$ $\mathrm{EP}$ at a low frequency means more significant protection for the underlying substrate (Fig. 7b1). It is noted that although 1.0\% $\mathrm{N}$-CDs-EP contains more N-CDs than $0.5 \% \mathrm{~N}$-CDs-EP, the protective effect on the steel substrate is similar. In the Bode plots, the low impedance modulus of the coatings at $Z_{\mathrm{f}=0.01 \mathrm{~Hz}}$ was generally utilized as an indicator of the barrier

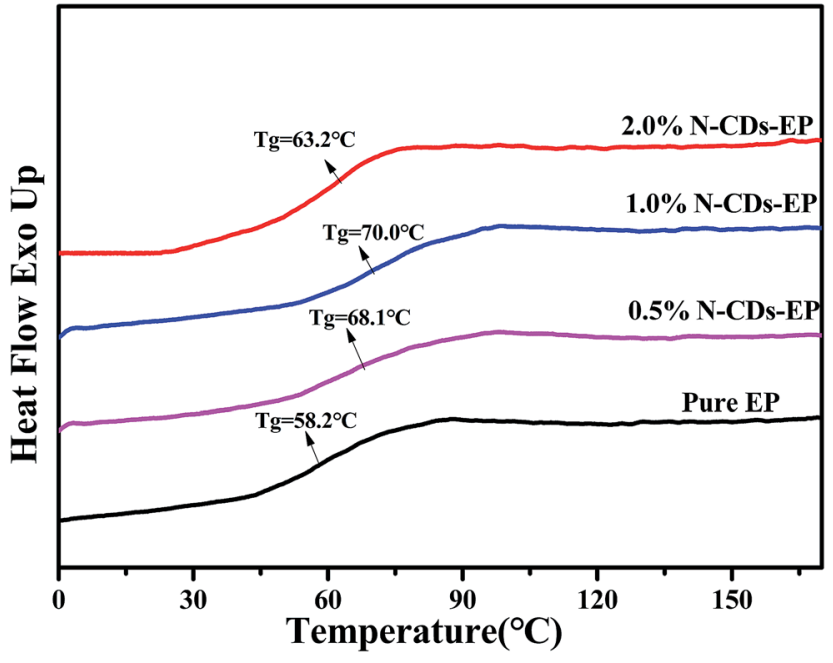

Fig. 6 DSC curves of the different coatings. 

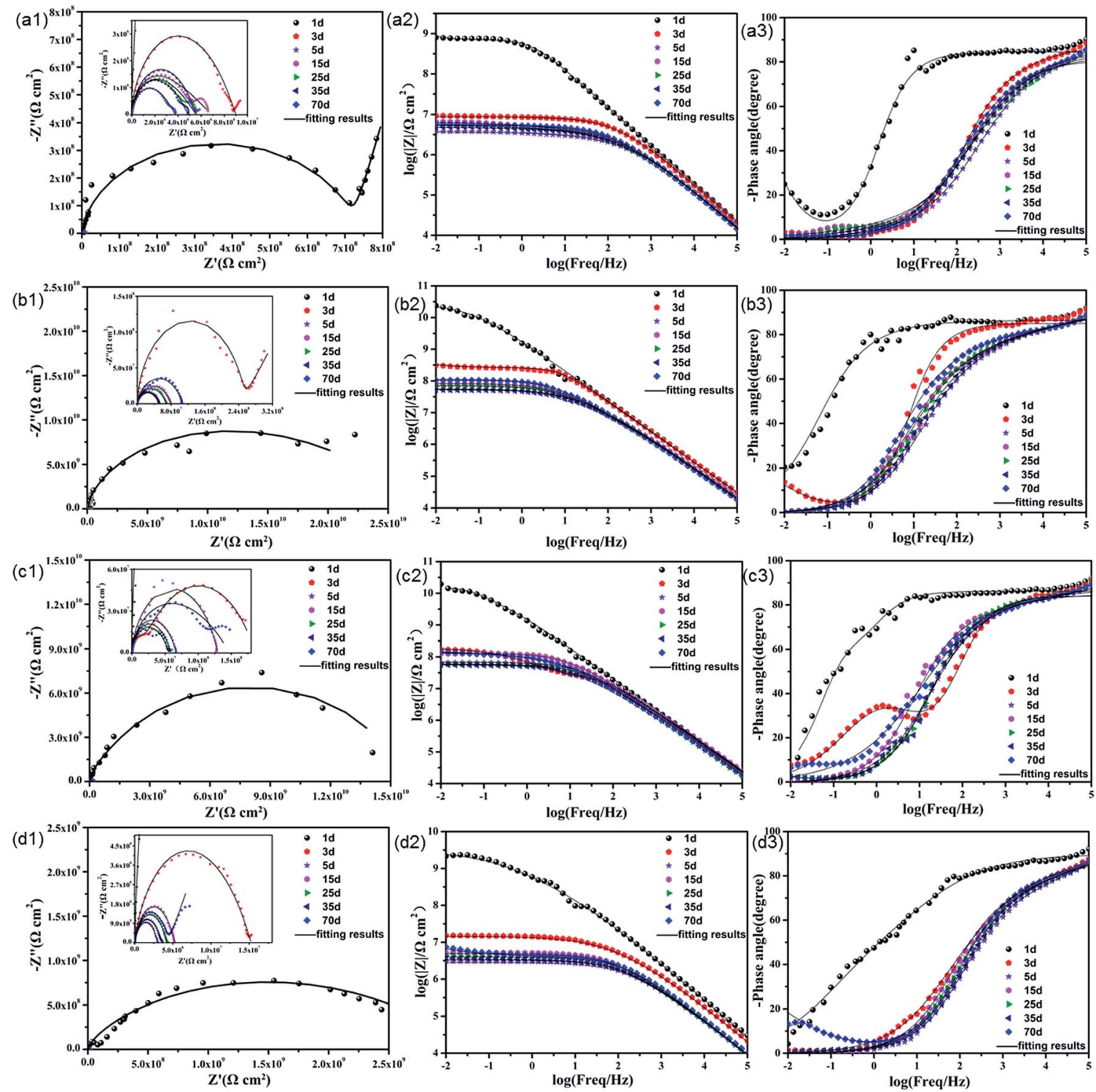

Fig. 7 Nyquist and Bode plots of (a) pure EP; (b) 0.5\% N-CDs-EP; (c) 1.0\% N-CDs-EP; and (d) 2.0\% N-CDs-EP coatings immersed in 3.5\% NaCl solution during 70 days (solid lines indicate fitting data).

performance. ${ }^{36}$ From Fig. 7a2, the values of the impedance after immersion for 70 days. The decreased impedance modulus $\left(Z_{\mathrm{f}=0.01 \mathrm{~Hz}}\right)$ of pure EP greatly decreased from $7.21 \times$ modulus is due to the fast failure of the pure EP coating, so the $10^{8} \Omega \mathrm{cm}^{2}$ at the beginning of immersion to $5.85 \times 10^{6} \Omega \mathrm{cm}^{2}$ steel substrates undergo corrosion in $\mathrm{NaCl}$ solution. At the
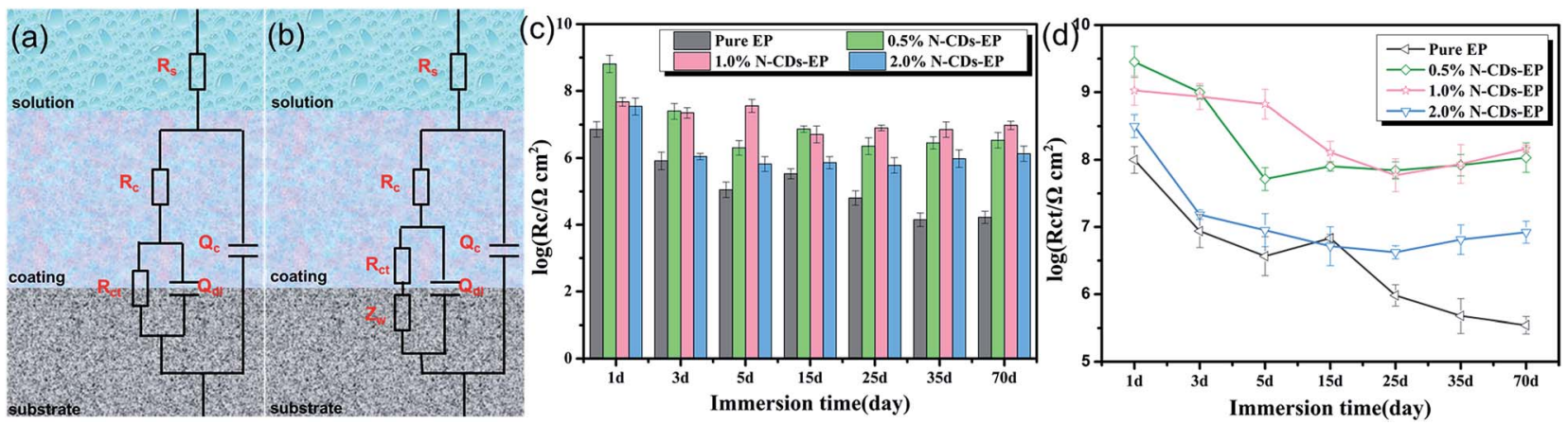

Fig. 8 (a) The electrical equivalent circuit models of stage I; (b) the electrical equivalent circuit models of stage II; (c) coating resistance ( $R_{\mathrm{c}}$ ); (d) charge transfer resistance $\left(R_{\mathrm{ct}}\right)$, respectively. 

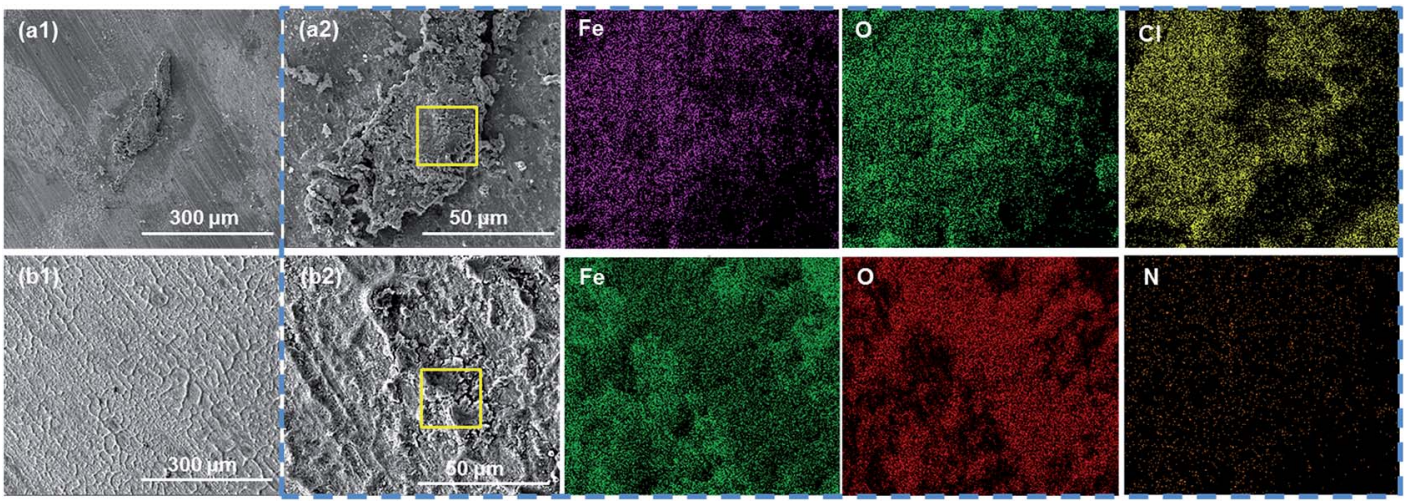

Fig. 9 The SEM morphological images of corrosion products on the substrate coated with (a1 and a2) pure EP and (b1 and b2) 0.5\% N-CDs-EP after 70 days of immersion. EDS is shown in the blue box.

beginning of immersion, the values of the impedance modulus $\left(Z_{\mathrm{f}=0.01 \mathrm{~Hz}}\right)$ for $0.5 \% \mathrm{~N}-\mathrm{CDs}-\mathrm{EP}$ and $1.0 \% \mathrm{~N}-\mathrm{CDs}-\mathrm{EP}$ were up to $\sim 10^{10} \Omega \mathrm{cm}^{2}$, higher than those of pure EP and $2.0 \%$ N-CDs-EP $\left(2.15 \times 10^{9} \Omega \mathrm{cm}^{2}\right)$ by order of an magnitude. It is demonstrated the N-CDs-EP system has a better barrier performance for steel substrates. In Fig. S5, $\uparrow$ the impedance modulus $\left(Z_{\mathrm{f}=0.01 \mathrm{~Hz}}\right)$ is $2.22 \times 10^{10} \Omega \mathrm{cm}^{2}$ for $0.5 \% \mathrm{~N}$-CDs-EP, $1.84 \times 10^{10} \Omega \mathrm{cm}^{2}$ for $1.0 \% \mathrm{~N}-\mathrm{CDs}-\mathrm{EP}$, and $2.15 \times 10^{9} \Omega \mathrm{cm}^{2}$ for $2.0 \% \mathrm{~N}-\mathrm{CDs}-\mathrm{EP}$ at the onset of immersion, respectively. After immersion for 70 days, the ultimate impedance modulus $\left(Z_{\mathrm{f}=0.01 \mathrm{~Hz}}\right)$ is $1.05 \times 10^{8} \Omega \mathrm{cm}^{2}$ for $0.5 \% \mathrm{~N}-\mathrm{CDs}-\mathrm{EP}, 1.48 \times 10^{8}$ $\Omega \mathrm{cm}^{2}$ for $1.0 \% \mathrm{~N}-\mathrm{CDS}-\mathrm{EP}$, and $7.18 \times 10^{6} \Omega \mathrm{cm}^{2}$ for $2.0 \% \mathrm{~N}-$ CDs-EP, respectively. The impedance modulus $\left(Z_{\mathrm{f}=0.01 \mathrm{~Hz}}\right)$ for $0.5 \% \mathrm{~N}-\mathrm{CDs}-\mathrm{EP}$ and $1.0 \% \mathrm{~N}-\mathrm{CDs}-\mathrm{EP}$ was always higher than $10^{8} \Omega \mathrm{cm}^{2}$ throughout the 70 days of immersion which showed that N-CDs can effectively improve the corrosion resistance of pure EP. However, excessive addition of N-CDs may result in coating defects which cause an inferior anti-corrosive performance. In addition, the long-term anticorrosion performance of N-CDs-EP coating systems could also be reflected by the phase angles during the entire immersion period, ${ }^{37}$ as shown in Fig. 7a3-d3. There are three peaks which could be approximately differentiated in the Bode-phase plots. Generally, the peak at high frequencies $\left(10^{4}-10^{5} \mathrm{~Hz}\right)$ corresponded to the responses of the coating, the peak at medium frequencies $\left(10^{0}-10^{3} \mathrm{~Hz}\right)$ was assigned to the responses of coating defects, and the peak at low frequency $\left(10^{-2}\right.$ to $\left.10^{0} \mathrm{~Hz}\right)$ could be attributed to steel substrate corrosion. ${ }^{38}$ In Fig. 7, the Bode phase angle plots present only one time constant in the highfrequency range at the beginning of immersion, which is associated with the response of all of the coating surfaces. However, the aggressive species had penetrated into the surface of steel substrates for pure EP after 1 day of immersion due to the hydrophilicity of the waterborne epoxy resin. Similarly, the sample of $2.0 \% \mathrm{~N}-\mathrm{CDs}-\mathrm{EP}$ results in a declining trend like pure EP (Fig. 7d3). For 1.0\% N-CDs-EP, the second time constant is pronounced, suggesting that the coating defects have gradually expanded (in medium frequency phase angles region) after long-term immersion. At the end of the immersion period, $0.5 \% \mathrm{~N}-\mathrm{CDs}-\mathrm{EP}$ provided sufficient protection for Q235 carbon steel, which was evident from the stabilized phase angles at high frequency and the highest resistance modulus values in Fig. $7 b .^{39}$ The coating can be evaluated from the breakpoint frequency value $\left(f_{\mathrm{b}}\right)$ in the Bodeimpedance modulus curve (Fig. S6 $\dagger$ ). The $f_{\mathrm{b}}$ value generally refers to the corresponding frequency value when the phase angle is $45^{\circ}$. The $f_{\mathrm{b}}$ value corresponds to the electrochemically active surface area (peeling area) of the electrode surface. The result proved that the N-CDs-EP coating had better adhesion to the carbon steel substrate.
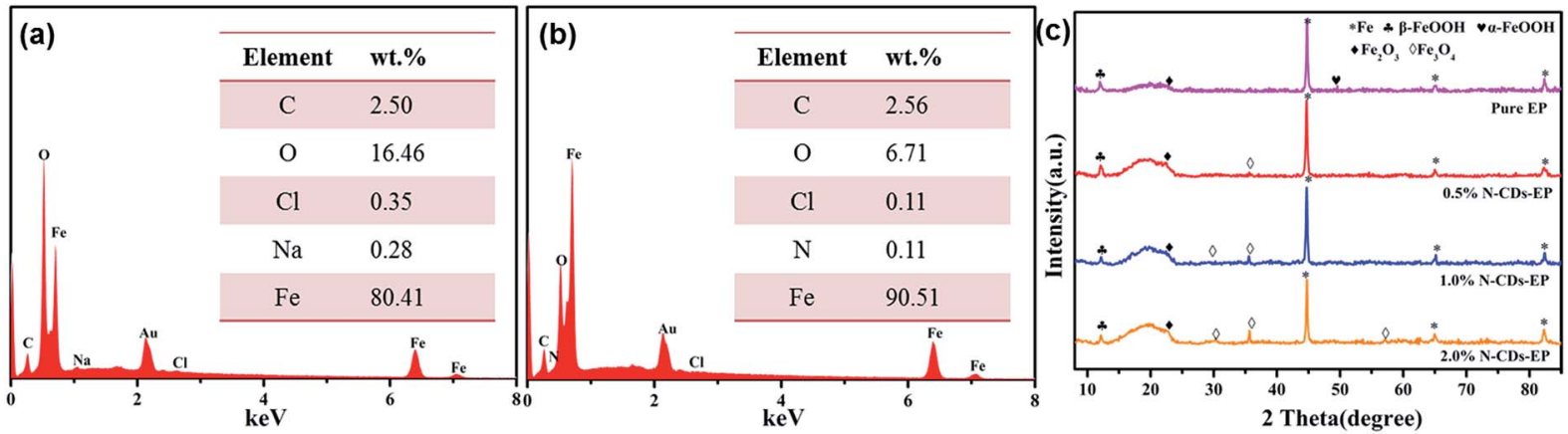

Fig. 10 The EDS spectra obtained from the areas shown in the yellow box in Fig. $9 a 2$ and b2 are presented in (a) and (b) and (c) the XRD patterns of the surface of steel substrates coated with different coatings after 70 days of immersion in $3.5 \mathrm{wt} \% \mathrm{NaCl}$ solution. 
In order to evaluate the corrosion protection properties of the various coating systems and judge the corrosion state, the EIS parameters were appropriately fitted with the electrical equivalent circuits using ZSimpwin software as shown in Fig. 8a and $\mathrm{b}$. This process included two stages. $R_{\mathrm{S}}$ and $R_{\mathrm{c}}$ represent the solution resistance and coating resistance. $R_{\mathrm{ct}}, Q_{\mathrm{c}}$ and $Q_{\mathrm{dl}}$ stand for the charge transfer resistance, coating capacitance and double layer capacitance, respectively. ${ }^{40}$ The Warburg element $\left(Z_{\mathrm{w}}\right)$ is used to reflect the diffusion in the coating. ${ }^{41}$ Due to the waterborne epoxy resin coatings absorbing water faster, the electrical equivalent circuit (Fig. 8a and b) was used to fit the electrochemical data for the sample where the corrosive medium had come into contact with the steel substrates. The fitted coating resistance $\left(R_{\mathrm{c}}\right)$ and charge transfer resistance of the double layer $\left(R_{\mathrm{ct}}\right)$ for different coating systems during the 70 days of immersion in $3.5 \mathrm{wt} \% \mathrm{NaCl}$ solution are shown in Fig. 8c and d. It was significant that the $R_{\mathrm{c}}$ and $R_{\mathrm{ct}}$ values of pure EP gradually decreased (from $7.24 \times 10^{6}$ to $1.67 \times 10^{4} \Omega \mathrm{cm}^{2}$ for $R_{\mathrm{c}}$ and from $9.98 \times 10^{7}$ to $3.48 \times 10^{5} \Omega \mathrm{cm}^{2}$ for $\left.R_{\mathrm{ct}}\right)$ and the rate of decrease was fast due to the sustained water absorption. However, upon adding 0.5-1.0 wt\% N-CDs, the nanocomposite coatings always maintained much higher values of $R_{\mathrm{c}}$ and $R_{\mathrm{ct}}$ and showed a slight decrease during the whole immersion period. ${ }^{42}$ In addition, the $R_{\mathrm{c}}$ and $R_{\mathrm{ct}}$ values of all the N-CDs-EP coating systems are one to three orders of magnitude much higher than those of the pure EP system. Therefore, we reach the following conclusion that embedding a moderate amount of $\mathrm{N}$-CDs could decrease coating flaws and increase diffusion hindrance of aggressive species in the coating matrix. However, excessive addition of $\mathrm{N}-\mathrm{CDs}$ (more than $1.0 \mathrm{wt} \%$ ) will destroy the coating structure and then lead to decreased $R_{\mathrm{c}}$ values. It is noted that the $R_{\mathrm{c}}$ and $R_{\mathrm{ct}}$ values of N-CDs-EP coatings show a slight increase at the end of the immersion period ${ }^{35}$ Because the N-CDs gradually filled up the defects of pure waterborne epoxy resin, the steel substrate was protected again in a short period. ${ }^{43}$

3.3.2 Rust layer analysis. After immersion for 70 days in $3.5 \mathrm{wt} \% \mathrm{NaCl}$ solution and electrochemical measurement, the polymer coatings were mechanically stripped off the steel substrates, and then the steel substrates were cleaned with ethyl alcohol and DI water several times to completely dislodge coating remnants. ${ }^{40}$ Subsequently, SEM-EDS analysis was used to investigate the surface morphologies of Q235 steel substrates coated with pure EP and 0.5\% N-CDs-EP (Fig. 9 and 10). As shown in Fig. 9a, a number of corrosion products were observed on the steel substrate coated with pure EP and it is obvious that the steel surface contained a lot of oxygen $(>15 \%)$ and chloride elements from the elemental compositions obtained by rust analysis (Fig. 10a). For the substrate coated with $0.5 \% \mathrm{~N}-\mathrm{CDs}-$ EP (Fig. 9b and 10b), a fresh dense layer with a uniform microstructure was formed on the substrate, which has enhanced the corrosion protection of the material. ${ }^{44}$ Moreover, EDS measurements (Fig. 10b) showed that the content of chloride and oxygen elements was less than $10 \%$ on the steel surface. There is a small quantity of nitrogen element on the steel surface which indicated the presence of $-\mathrm{NH}_{2}$ from $\mathrm{N}-\mathrm{CDS}$ absorbed in the fresh densest layer. In addition, XRD patterns

\section{Filling inherent defects Corrosion inhibition}

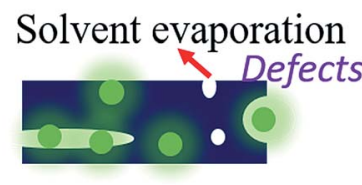

Bond interaction

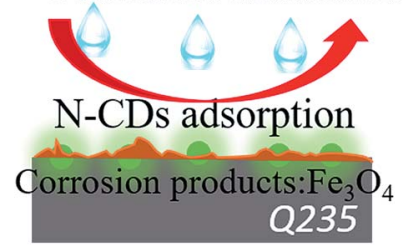

Fig. 11 Corrosion resistance mechanism of the N-CDs-EP coating.

were recorded to further confirm the presence of corrosion products on the substrate surface after the films were peeled off after 70 days of immersion in $3.5 \% \mathrm{NaCl}$ solution, ${ }^{43}$ as shown in Fig. 10c. The infiltration of rich electrolyte ions through the pure waterborne epoxy coating is attributed to the corrosion product composed of hematite $\left(\mathrm{Fe}_{2} \mathrm{O}_{3}\right)$, unstable goethite $(\alpha$ $\mathrm{FeOOH})$ and stable akaganeite $(\beta-\mathrm{FeOOH})$. However, the rust product was mainly composed of magnetite $\left(\mathrm{Fe}_{3} \mathrm{O}_{4}\right)$ which formed an obvious passivation layer after the addition of $\mathrm{N}-\mathrm{CDS}$ to the coating. ${ }^{45}$ The N-CD nanoparticles assist the formation of passive oxides on the substrate surface and resist the penetration of incursive anions such as oxygen, chloride, and water through the coating to the steel.

3.3.3 Corrosion resistance mechanism of coatings. The imaginary corrosion mechanisms of the composite coating system are exhibited in Fig. 11. First of all, bond interactions which include hydrogen bonding, van der Waals forces and covalent bonding between contiguous N-CDs, and between $\mathrm{N}$ CDs and polymer chains can make the waterborne epoxy network denser, thus enhancing the anti-corrosion performance. ${ }^{21}$ Next in importance, as a kind of nano-filler, a suitable amount of N-CDs was added to the structure of the waterborne epoxy resin coating, so as to fill the voids and defects caused by the evaporation of water during curing. Finally, N-CDs in contact with the surface of the substrate may adsorb on the Q235 carbon steel surface through physical adsorption and chemisorption to form a dense $\mathrm{Fe}_{3} \mathrm{O}_{4}$ passivation film which can reduce corrosion. According to the theory of metal passivation, passivation is the formation of a dense passivation film with good surface coverage, thereby improving the anti-flaking properties of the oxide film to enhance the oxidation resistance of the protective coating.

\section{Conclusion}

To conclude, we synthesized N-CD nanoparticles having excellent solubility in ethanol by a hydrothermal method. The diameter and height of N-CDs were observed to be approximately 3-5 $\mathrm{nm}$ by scanning probe microscopy and transmission 
electron microscopy. The waterborne epoxy resin coatings containing $0.5 \mathrm{wt} \%, 1 \mathrm{wt} \%$, and $2 \mathrm{wt} \% \mathrm{~N}-\mathrm{CD}$ nanoparticles were favorably prepared by the curing reaction of aqueous amine curing agents, epoxy resin (E51), and N-CDs. The corrosion resistance performance of coatings without and with N-CDs on steel electrodes was studied by impedance measurements and fitting $R_{\mathrm{c}}$ and $R_{\mathrm{ct}}$ by immersing them in $3.5 \mathrm{wt} \% \mathrm{NaCl}$ solution. The composite coatings containing $0.5-1 \mathrm{wt} \% \mathrm{~N}-\mathrm{CDs}$ showed better corrosion resistance performance for Q235 steel than the pure EP coating which is definitely discovered from a high phase angle at high frequency and low impedance modulus at $0.01 \mathrm{~Hz}\left(Z_{\mathrm{f}=0.01 \mathrm{~Hz}}\right)$ in EIS, and the formation of compact $\mathrm{Fe}_{2} \mathrm{O}_{3}$ and $\mathrm{Fe}_{3} \mathrm{O}_{4}$ passivation layers is also observed by analyzing the surface morphology and chemical composition of Q235. Meanwhile, the mechanism of N-CDs enhancing the corrosion resistance of waterborne epoxy resin coatings is discussed. Based on our research conclusions, we consider that N-CDs have great potential to improve the corrosion resistance of waterborne epoxy coatings due to the environmental requirements of low VOC.

\section{Conflicts of interest}

There are no conflicts to declare.

\section{Acknowledgements}

The authors gratefully acknowledged financial support provided by the Open Financial Grant from the Qingdao National Laboratory for Marine Science and Technology (QNLM2016ORP0409).

\section{Notes and references}

1 Z. Jia, P. Xiong, Y. Shi, W. Zhou, Y. Cheng, Y. Zheng, T. Xi and S. Wei, J. Mater. Chem. B, 2016, 4, 2498-2511.

2 L. Hamadi, S. Mansouri, K. Oulmi and A. Kareche, Egypt. J. Pet., 2018, 27, 1157-1165.

3 B. Jin, D.-B. Xiong, Z. Tan, G. Fan, Q. Guo, Y. Su, Z. Li and D. Zhang, Carbon, 2019, 142, 482-490.

4 A. Kabir, M. J. Dunlop, B. Acharya, R. Bissessur and M. Ahmed, Polymers, 2018, 10, 16.

5 M. Li, N. Liu, J. Chen and Q. Li, J. Taiwan Inst. Chem. Eng., 2019, 95, 682-691.

6 F. Jiang, W. Zhao, Y. Wu, J. Dong, K. Zhou, G. Lu and J. Pu, Prog. Org. Coat., 2019, 127, 70-79.

7 Y.-T. Choi, S. B. Kim, S. J. Lee, G.-T. Kim, E.-H. Park and E.-S. Park, Composites, Part B, 2017, 114, 268-279.

8 S. Ataei, S. N. Khorasani and R. E. Neisiany, Prog. Org. Coat., 2019, 129, 77-95.

9 A. Weishaar, M. Carpenter, R. Loucks, A. Sakulich and A. M. Peterson, Constr. Build. Mater., 2018, 191, 125-135.

10 C. Zhang, H. Wang and Q. Zhou, Prog. Org. Coat., 2018, 125, 403-410.

11 S. Mandal, N. Pandey, S. Singh, A. Ranjanb and U. Ojha, Mater. Chem. Front., 2019, 3, 690-701.
12 M. Shibata, N. Ishigami and A. Shibita, React. Funct. Polym., 2017, 118, 35-41.

13 S. He, W. Q. Liu, M. P. Yang, C. H. Liu, C. Jiang and Z. F. Wang, J. Appl. Polym. Sci., 2019, 136, 10.

14 L. Guo, L. Z. Jing, Y. Liu, B. J. Zou, S. C. Hua, J. P. Zhang, D. Y. Yu, S. C. Wang, S. R. Wang, L. D. Wang and J. X. Yang, Int. J. Electrochem. Sci., 2018, 13, 11867-11881.

15 M. Liu, S. Han, J. Pan and W. Ren, Constr. Build. Mater., 2018, 177, 72-82.

16 C. Hu, J. Zhao, Z. Leng, M. N. Partl and R. Li, Constr. Build. Mater., 2019, 197, 220-227.

17 J. Shen, Y. Zhu, X. Yang, J. Zong, J. Zhang and C. Li, New J. Chem., 2012, 36, 97-101.

18 J. H. Shen, Y. H. Zhu, C. Chen, X. L. Yang and C. Z. Li, Chem. Commun., 2011, 47, 2580-2582.

19 Y. Song, C. Z. Zhu, J. H. Song, H. Li, D. Du and Y. H. Lin, ACS Appl. Mater. Interfaces, 2017, 9, 7399-7405.

20 M. Cui, S. Ren, H. Zhao, L. Wang and Q. Xue, Appl. Surf. Sci., 2018, 443, 145-156.

21 C. Zhu, Y. Fu, C. Liu, Y. Liu, L. Hu, J. Liu, I. Bello, H. Li, N. Liu, S. Guo, H. Huang, Y. Lifshitz, S.-T. Lee and Z. Kang, Adv. Mater., 2017, 29, 1701399.

22 H. Singh, J. S. Sidhu, D. K. Mahajan and N. Singh, Mater. Chem. Front., 2019, 3, 476-483.

23 T. Monetta, A. Acquesta, A. Carangelo and F. Bellucci, J. Coat. Technol. Res., 2018, 15, 923-931.

24 W. Shang, T. Cai, Y. Zhang, D. Liu and S. Liu, Tribol. Int., 2018, 118, 373-380.

25 W. Shang, M. Ye, T. Cai, L. Zhao, Y. Zhang, D. Liu and S. Liu, J. Mol. Liq., 2018, 266, 65-74.

26 M. Ye, T. Cai, W. Shang, L. Zhao, Y. Zhang, D. Liu and S. Liu, Tribol. Int., 2018, 127, 557-567.

27 K. Jiang, Y. Wang, X. Gao, C. Cai and H. Lin, Angew. Chem., Int. Ed., 2018, 57, 6216-6220.

28 K. Jiang, Y. Wang, C. Cai and H. Lin, Adv. Mater., 2018, 30, 1800783.

29 S. Zhu, Q. Meng, L. Wang, J. Zhang, Y. Song, H. Jin, K. Zhang, H. Sun, H. Wang and B. Yang, Angew. Chem., Int. Ed., 2013, 52, 3953-3957.

30 Y. Xu, M. Wu, Y. Liu, X.-Z. Feng, X.-B. Yin, X.-W. He and Y.-K. Zhang, Chem.-Eur. J., 2013, 19, 2276-2283.

31 C. Chen, S. Qiu, M. Cui, S. Qin, G. Yan, H. Zhao, L. Wang and Q. Xue, Carbon, 2017, 114, 356-366.

32 J. Macan, K. Paljar, B. Burmas, G. Spehar, M. Leskovac and A. Gajovic, J. Therm. Anal. Calorim., 2017, 127, 399-408.

33 S. L. Qin, M. J. Cui, Z. D. Dai, S. H. Qiu, H. C. Zhao, L. P. Wang and A. F. Zhang, Tribol. Lett., 2018, 66, 10.

34 S. Qiu, W. Li, W. Zheng, H. Zhao and L. Wang, ACS Appl. Mater. Interfaces, 2017, 9, 34294-34304.

35 J.-H. Ding, H.-R. Zhao, Y. Zheng, X. Zhao and H.-B. Yu, Carbon, 2018, 138, 197-206.

36 P. Du, J. Wang, G. Liu, H. Zhao and L. Wang, Mater. Chem. Front., 2019, 3, 321-330.

37 P. Du, S. Qiu, C. Liu, G. Liu, H. Zhao and L. Wang, New J. Chem., 2018, 42, 4201-4209.

38 W. Sun, L. D. Wang, T. T. Wu, C. Dong and G. C. Liu, Mater. Lett., 2019, 240, 262-266. 
39 T. Wang, L. Tan, C. Ding, M. Wang, J. Xu and J. Fu, J. Mater. Chem. A, 2017, 5, 1756-1768.

40 H. Zhao, J. Ding and H. Yu, New J. Chem., 2018, 42, 1443314443.

41 J. Ding, O. u. Rahman, W. Peng, H. Dou and H. Yu, Appl. Surf. Sci., 2018, 427, 981-991.

42 S. K. Saha and P. Banerjee, Mater. Chem. Front., 2018, 2, 1674-1691.
43 C. Chen, S. Qiu, S. Qin, G. Yan, H. Zhao and L. Wang, Int. J. Electrochem. Sci., 2017, 12, 3417-3431.

44 J. Ding, H. Zhao, D. Ji, B. Xu, X. Zhao, Z. Wang, D. Wang, Q. Zhou and H. Yu, J. Mater. Chem. A, 2019, 7, 2864-2874.

45 S. H. Qiu, C. Chen, M. J. Cui, W. Li, H. C. Zhao and L. P. Wang, Appl. Surf. Sci., 2017, 407, 213-222. 